\title{
The analgesic efficacy of a single injection of ultrasound-guided retrolaminar paravertebral block for breast surgery: a prospective, randomized, double-blinded study
}

\author{
Boo-Young Hwang ${ }^{1,2}$, Eunsoo Kim ${ }^{1,2}$, Jae-young Kwon ${ }^{1}$, Ji-youn Lee ${ }^{1}$, Dowon Lee ${ }^{1}$, Eun Ji Park ${ }^{1}$, and \\ Taewoo Kang ${ }^{3}$
}

'Department of Anesthesia and Pain Medicine, Pusan National University School of Medicine, Yangsan, Korea

${ }^{2}$ Department of Anesthesia and Pain Medicine, Biomedical Research Institute, Pusan National University Hospital, Busan, Korea

${ }^{3}$ Department of Busan Cancer Center (Breast Cancer Clinic), Pusan National University Hospital, Busan, Korea

Received February 20, 2020

Revised June 25, 2020

Accepted July 14, 2020

Handling Editor: Jee Youn Moon

\section{Correspondence}

Eunsoo Kim

Department of Anesthesia and Pain Medicine, Pusan National University Hospital, 179 Gudeok-ro, Seo-gu, Busan 49241, Korea

Tel: +82-51-240-7274

Fax: +82-51-240-7466

E-mail: eunsookim@pusan.ac.kr

Previous presentation at conference This article was presented at the European Anesthesiology Congress 2014 on June 2, 2014, in Stockholm, Sweden.
Background: The thoracic paravertebral block is an effective analgesic technique for postoperative pain management after breast surgery. The ultrasound-guided retrolaminar block (RLB) is a safer alternative to conventional paravertebral block. Thus, we assessed the analgesic efficacy of ultrasound-guided RLB for postoperative pain management after breast surgery.

Methods: Patients requiring breast surgery were randomly allocated to group $\mathrm{C}$ (retrolaminar injection with saline) and group R (RLB with local anesthetic mixture). The RLB was performed at the level of T3 with local anesthetic mixture $(0.75 \%$ ropivacaine $20 \mathrm{~mL}+2 \%$ lidocaine $10 \mathrm{~mL}$ ) under general anesthesia before the skin incision. The primary outcome was cumulative morphine consumption using intravenous patient-controlled analgesia (IV-PCA) at 24 hour postoperatively. The secondary outcomes were the visual analogue scale (VAS) scores at 1, 6, 24, and 48 hour postoperatively and the occurrence of adverse events and patient satisfaction after the surgery.

Results: Forty-six patients were included, 24 in group C and 22 in group R. The cumulative morphine consumption using IV-PCA did not differ between the two groups $(P=0.631)$. The intraoperative use of remifentanil was higher in group $C$ than in group $\mathrm{R}(P=0.025)$. The resting and coughing VAS scores at 1 hour postoperatively were higher in group $\mathrm{R}$ than in group $\mathrm{C}(P=0.011, P=0.004)$. The incidence of adverse events and patient satisfaction was not significantly different between the two groups.

Conclusions: A single injection of ultrasound-guided RLB did not reduce postoperative analgesic requirements following breast surgery.

Key Words: Analgesics, Opioid; Anesthetics, Local; Breast Neoplasms; Injections, Spinal; Nerve Block; Pain, Postoperative; Ropivacaine; Ultrasonography, Interventional; Visual Analog Scale. (a) This is an open-access article distributed under the terms of the Creative Commons Attribution Non-Commercial License (http://creativecommons.org/licenses/by-nc/4.0/), which permits unrestricted non-commercial use, distribution, and reproduction in any medium, provided the original work is properly cited.

(c) The Korean Pain Society, 2020
Author contributions: Boo-Young Hwang: Writing/manuscript preparation; Eunsoo Kim: Writing/manuscript preparation; Jae-young Kwon: Study conception; Ji-youn Lee: Investigation; Dowon Lee: Formal analysis; Eun Ji Park: Investigation; Taewoo Kang: Investigation. 


\section{INTRODUCTION}

Breast cancer is one of the most frequently occurring cancers in women. Surgical excision is the primary treatment for breast cancer, even in stage IV cases [1]. Surgery increases the survival rate, while a high percentage of patients who undergo mastectomy suffer from postsurgical pain [2]. Inadequate pain control causes high opioid consumption, leading to several complications, such as nausea, vomiting, and impaired patient recovery and quality of life [3]. In addition, severe acute pain can lead to persistant postoperative pain after breast surgery [4].

The thoracic paravertebral block (TPVB) is a well-established regional analgesic technique for breast surgery. This block can reduce postoperative pain and opioid consumption [5]. However, when employing the conventional TPVB using the anatomical landmark technique, it can be technically difficult to identify the thoracic paravertebral space (TPVS). This analgesic technique can cause complications, such as inadvertent pleural puncture, unintended epidural spread, accidental vascular injection of local anesthetic, intrathecal injection, and postural headache [6]. Although recent studies on ultrasound-guided TPVB reported a low incidence rate $(0.7 \%)$ of complications [7], serious problems such as intrathecal injection or pleural puncture could occur even when using ultrasound $[8,9]$. Moreover, the failure rate of this block with ultrasound guidance was similar to that of the landmark technique (5.3\% vs. 5.6\%) [5]. Also, the ultrasound-guided procedure might require some proficiency compared to the landmark method.

The retrolaminar block (RLB), which was first introduced by Pfeiffer et al. [10], is a modified paravertebral block that administers local anesthetic between the lamina of the thoracic vertebra and the erector spinae muscles, using landmark technique or under ultrasound guidance, rather than entering the needle into the TPVS directly. Moreover, real-time ultrasound guidance can help identify the lamina and monitor the spread of local anesthetic [11]. Previous studies indicated that the RLB could be an easy, safe, and effective analgesic technique for breast surgery [11-14]. However, there have been a few randomized, double-blinded studies on the efficacy of RLB for analgesia after breast surgery $[13,14]$. These studies did not apply ultrasound guidance for RLB. We hypothesized that ultrasound-guided RLB could reduce postoperative pain and the opioid requirement after breast surgery. Therefore, we evaluated the analgesic efficacy of a single injection of ultrasound-guided RLB for postoperative pain management following breast surgery.

\section{MATERIALS AND METHODS}

\section{Study design}

A prospective, randomized, and double-blind study was conducted at the Department of Anesthesia and Pain Medicine at Pusan National University Hospital, Korea between September and December 2013 of Pusan National University Hospital (No. H-1308-014-018). All patients provided informed consent.

\section{Participants}

A total of 64 patients aged between 18 and 75 years, with American Society of Anesthesiologists physical status class (ASA) I and II, who were scheduled for modified radical mastectomy and quadrantectomy, were assessed for inclusion in this study. This study excluded patients with the following conditions: coagulopathy, infection at the injection site, history of allergy to local anesthetics, morphine, pregnancy, breastfeeding, severe obesity (body mass index $>35 \mathrm{~kg} / \mathrm{m}^{2}$ ), major psychosis, drug and alcohol abuse, chronic pain or long-term opioid use over 90 days, history of significant neurological, psychiatric, neuromuscular, cardiovascular, pulmonary, renal, or hepatic disease, as well as those with a language barrier. Patients were randomly allocated to two groups with block randomization using a computer-generated random number list. We used blocked randomization, and the block size was four. Group $\mathrm{C}$, the control group, received a retrolaminar injection with $30 \mathrm{~mL}$ of normal saline and intravenous patient-controlled analgesia (IV-PCA) for postoperative pain management. Group R received a single injection of the RLB with $30 \mathrm{~mL}$ of local anesthetic mixture $(0.75 \%$ ropivacaine 20 $\mathrm{mL}+2 \%$ lidocaine $10 \mathrm{~mL}$ ) and IV-PCA. We planned to use a mixture of ropivacaine and lidocaine to reduce the onset time of the RLB without reducing postoperative analgesia duration $[15,16]$.

For the double-blinded method, the patients received ultrasound-guided RLB immediately after the induction of anesthesia. A nurse who did not participate in this study prepared a syringe filled with $30 \mathrm{~mL}$ of local anesthetic mixture $(0.75 \%$ ropivacaine $20 \mathrm{~mL}+2 \%$ lidocaine $10 \mathrm{~mL})$ or normal saline before the induction of anesthesia according to the computer-generated random number list. Moreover, an anesthesiologist who did not participate in the study recorded the outcome variables.

\section{Intervention}

All patients underwent standard hemodynamic monitoring and induction of general anesthesia with an effect-site 
concentration of 3-4 $\mu \mathrm{g} / \mathrm{mL}$ propofol and 3-6 $\mathrm{ng} / \mathrm{mL}$ remifentanil, using a target-controlled infusion device (Injectomat TIVA Agilia; Fresenius Kabi, Bad Homburg, Germany) and $0.6 \mathrm{mg} / \mathrm{kg}$ rocuronium. After induction of anesthesia, the patient was turned to the lateral decubitus position with the surgical side up. The anesthesiologist placed the ultrasound probe (6-13 MHz HFL38x or 2-5 MHz C60xi; Fujifilm SonoSite, Bothell, WA) parallel to the spine, which was selected according to body habitus, $5 \mathrm{~cm}$ lateral to the spinous processes, and counted the ribs from the first rib in a downward direction. The probe moved medially until continuous flat hyperechoic structures with regularly interposed small notches appeared when it reached the level of the third rib. A 20-gauge Tuohy needle connected to a syringe containing the anesthetic mixture or saline was advanced from the caudal to cephalad direction until contact with the lamina of the third thoracic vertebra was achieved (Fig. 1). The spread of the solution was visualized between the paraspinal muscle and lamina while the mixture was administered with intermittent aspirations every $5 \mathrm{~mL}$. A single anesthesiologist performed all regional analgesic procedures to reduce interindividual differences.

After a single injection of the RLB, the patient was placed in the supine position and the surgical intervention for breast cancer was performed. Propofol was maintained within the target range (bispectral index 40-60) and remifentanil was controlled within the range of $\pm 20 \%$ of the baseline mean blood pressure and heart rate. Postoperative pain was managed using only IV-PCA. For proper pain control, a PCA device (GemStar ${ }^{\circledR}$ Infusion System; Hospira, Lake Forest, IL) was set up as follows: patient demand mode $2 \mathrm{~mL}$ (morphine sulfate $0.5 \mathrm{mg} / \mathrm{mL}$ ) without a background infusion, a lock-out interval of 5 minutes, and a 4-hours limit of $40 \mathrm{~mL}$. This device started to work immediately after surgery, and continued until 48 hours postoperatively. All patients received morphine sulfate 3 $\mathrm{mg}$ for the loading dose and $0.3 \mathrm{mg}$ ramosetron intravenously 30 minutes before the completion of the surgery.

\section{Assessment}

The primary outcome of this study was the comparison of cumulative morphine consumption using PCA pumps at 24 hours postoperatively. The secondary outcomes were morphine consumption at 1,6 , and 48 hours postoperatively, the visual analogue scale (VAS) scores during resting and coughing at 1, 6, 24, and 48 hours postoperatively, and the occurrence of adverse events, such as postoperative nausea and vomiting (PONV), respiratory depression (SpO2 < 90\%), systemic toxicity of local anesthetics (circumoral paresthesia, tongue paresthesia, dizziness, tinnitus, blurred vision, excitatory signs, and seizure), and Horner's syndrome. Patient satisfaction was assessed 48 hours after the surgery according to the following scale: $1=$ very unsatisfactory, $2=$ unsatisfactory, $3=$ neutral, $4=$ satisfactory, and $5=$ very satisfactory. An anesthesiologist who was blinded for the analgesic procedure and induction of anesthesia, recorded the data with the follow-up visit at 1, 6, 24, and 48 hours postoperatively.

\section{Statistical analysis}

The number of subjects was calculated based on a previous paravertebral block study [17]. In the previous study, the dose of tramadol in the general anesthesia group was $176.67 \pm 52.08 \mathrm{mg}$. Assuming a clinically meaningful reduction of $25 \%$ in opioid consumption 24 hours postoperatively, we estimated that the sample size should be 20 in each group from a power (1- $\beta$ ) of $80 \%$ at an alpha-level of 0.05 based on effect size of 0.9 , a difference of $45 \mathrm{mg}$, and standard deviation of 50 . The study was conducted on 50 patients considering an exclusion rate of $20 \%$ (each group consisted of 25 patients).

The Shapiro-Wilk method was used for a normality test. Normally distributed data were analyzed using the independent $t$-test and repeated measures analysis of variance (ANOVA), and non-parametric data were analyzed using the Mann-Whitney $U$-test and rank transform for non-parametric factorial analyses. Continuous data were
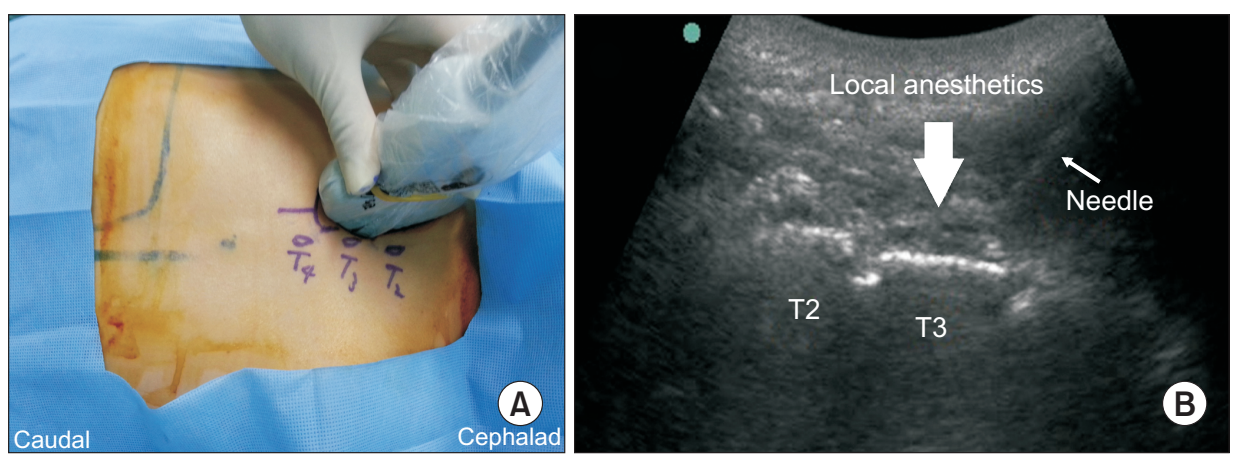

Fig. 1. (A) Proper longitudinal position of the curvilinear transducer with skin markings for the retrolaminar block. (B) Ultrasound image demonstrating the relationship of the vertebral lamina to needle placement with spreading local anesthetics during the retrolaminar block. T2: second thoracic vertebra, T3: third thoracic vertebra. 


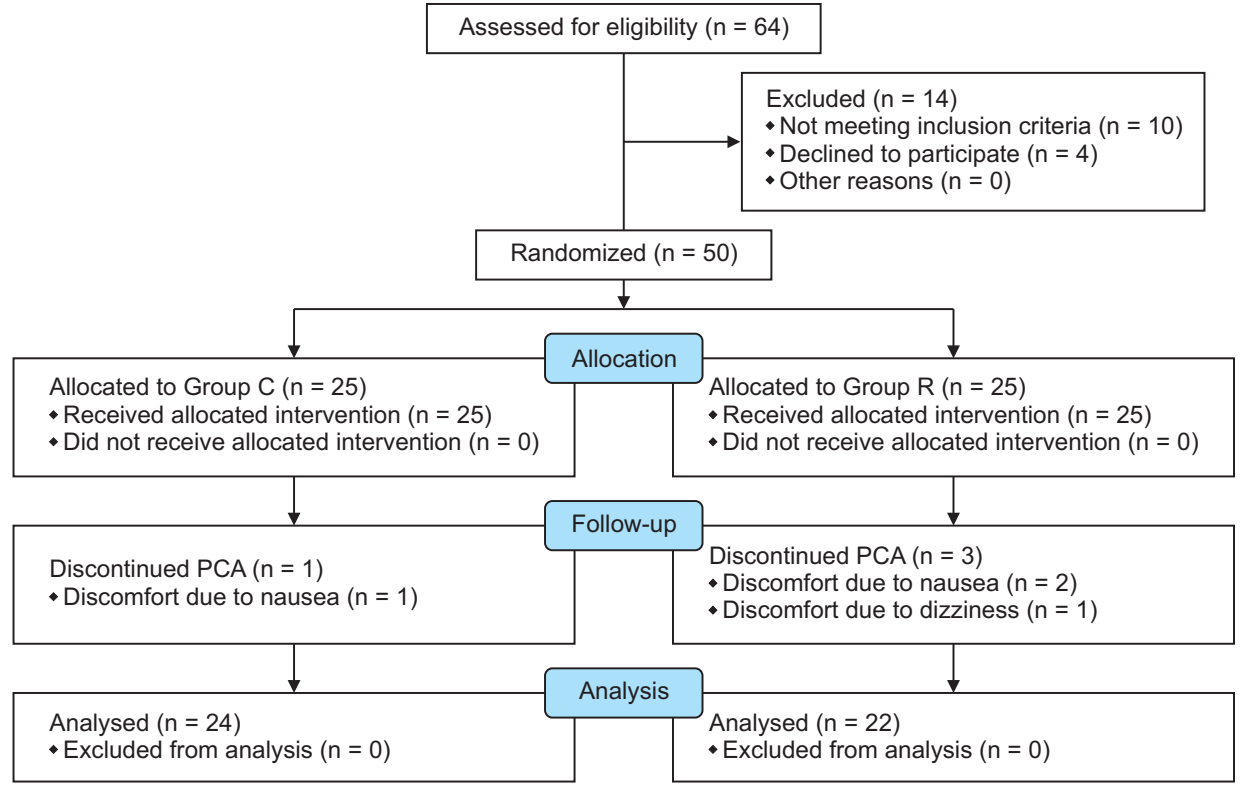

Fig. 2. Study flow chart with specific causes of study interruptions and dropouts. The flow chart of this study is based on the CONSORT Statement. Group C: retrolaminar injection with saline, Group R: retrolaminar block with local anesthetics, PCA: controlled analgesia. described as mean \pm standard deviation or median \pm interquartile range, and categorical data as number (percentages). A probability of $<0.05$ was considered significant. The IBM SPSS Statistics ver. 21.0 (IBM Co., Armonk, NY) was used for all statistical analyses.

\section{RESULTS}

A total of 64 patients were assessed for inclusion in this study. Ten patients who did not meet the inclusion criteria were excluded (anticoagulant use, $\mathrm{n}=3$; pulmonary disease, $\mathrm{n}=3$; anxiety disorders, $\mathrm{n}=2$; heart disease, $\mathrm{n}=1$; noncommunicable foreigner, $n=1$ ). Further, four patients declined participation in the study. Thus, we included 50 patients in the study and divided them into two groups. One patient in group $\mathrm{C}$ and two patients in group $\mathrm{R}$ discontinued PCA on their own because of nausea, and one patient in group R due to dizziness. Accordingly, 24 patients in group $\mathrm{C}$ and 22 patients in group $\mathrm{R}$ completed the final analysis (Fig. 2).

The demographic and clinical characteristics of both the groups are presented in Table 1. There were no significant differences in ASA, Apfel score, age, height, weight, body mass index, duration of surgery, propofol consumption, and the type of surgery between the two groups. The total intraoperative dose of remifentanil was higher in group $\mathrm{C}$ than in group $\mathrm{R}(P=0.025)$. The incidence of adverse events and patient satisfaction were not significantly different between the two groups (Tables 2,3).

The VAS scores in the postoperative period decreased in both the groups with time (Fig. 3). However, the VAS scores during resting and coughing 1 hour postoperatively were higher in group $\mathrm{C}$ than in group $\mathrm{R}(P=0.011, P=0.004)$. The total consumption of morphine with IV-PCA at 1, 6, 24 and 48 hours postoperatively did not differ between the two groups $(P=0.63$, Fig. 4$)$.

\section{DISCUSSION}

This clinical study evaluated the efficacy of a single injection of ultrasound-guided RLB for postoperative pain management in patients undergoing breast surgery. The RLB group had a lower requirement of remifentanil than the control group intraoperatively. In addition, the VAS scores during resting or coughing 1 hour postoperatively were lower in the RLB group than in the control group. However, the total consumption of morphine 24 hours after the surgery did not show a statistically significant difference between the two groups, and the occurrence of adverse events, such as PONV did not differ considerably between the groups. Therefore, the addition of a single injection of ultrasound-guided RLB to conventional treatment, such as IV- PCA, did not show clinically significant improvement in postoperative pain management in patients undergoing breast surgery.

In our study, a single injection of ultrasound-guided RLB resulted in lower pain scores immediately after surgery, but it did not have the advantage of reducing morphine consumption postoperatively. This result is in agreement with previously published studies regarding the classic TPVB and RLB. A retrospective study by Agarwal et al. [18] showed that a single injection of the classic TPVB for mastectomy could decrease pain scores in the immediate postoperative period, but did not show a beneficial effect 
Table 1. Patient and Clinical Characteristics

\begin{tabular}{lccc}
\hline \multicolumn{1}{c}{ Characteristic } & Group C $(\mathrm{n}=24)$ & Group R $(\mathrm{n}=22)$ & $P$ value \\
\hline ASA classification (I/II) & $17 / 7(70.8 / 29.2)$ & $12 / 10(54.5 / 45.5)$ & 0.087 \\
Apfel score & $2(8.3)$ & 0 & 0.288 \\
1 & $13(54.2)$ & $16(72.7)$ & $4(18.2)$ \\
2 & $8(33.3)$ & $2(9.1)$ & 0.368 \\
3 & $1(4.2)$ & $54.7 \pm 10.7$ & 0.794 \\
4 & $49.8 \pm 8.5$ & $154.7 \pm 17.4$ & 0.241 \\
Age $(\mathrm{yr})$ & $151.6 \pm 23.5$ & $62.7 \pm 22.9$ & 0.221 \\
Height $(\mathrm{cm})$ & $59.8 \pm 20.1$ & $23.6 \pm 3.1$ & 0.780 \\
Weight $(\mathrm{kg})$ & $23.0 \pm 3.7$ & $180.0 \pm 33.8$ & 0.697 \\
BMI (kg/m $\left.{ }^{2}\right)$ & $160.0 \pm 30.0$ & $150.0 \pm 34.5$ & $0.025^{*}$ \\
Duration of anesthesia (min) & $135.0 \pm 41.3$ & $618.5 \pm 218.0$ & 0.151 \\
Duration of surgery (min) & $663.5 \pm 300.5$ & $1,032.1 \pm 205.0$ & 0.271 \\
Remifentanil consumption $(\mu \mathrm{gg})$ & $1,076.4 \pm 286.1$ & $8(36.4)$ & \\
Propofol consumption $(\mathrm{mg})$ & $7(29.2)$ & $14(63.6)$ & \\
Operation & $17(70.8)$ & & \\
$\quad$ MRM & & & \\
Quadrantectomy & & & \\
\hline
\end{tabular}

Data are presented as number (\%) or mean \pm standard deviation.

There were no differences in ASA classification, Apfel score, age, height, weight, BMI, duration of surgery, propofol consumption, and operation type between the groups.

Group C: retrolaminar injection with saline, Group R: retrolaminar block with local anesthetics, ASA: American Society of Anesthesiologists, BMI: body mass index, MRM: modified radical mastectomy.

$* P<0.05$.

Table 2. Incidence of Adverse Events

\begin{tabular}{llccc}
\hline \multicolumn{1}{c}{ Side effect } & & $\begin{array}{c}\text { Group C } \\
(\mathrm{n}=24)\end{array}$ & $\begin{array}{c}\text { Group R } \\
(\mathrm{n}=22)\end{array}$ & $P$ value \\
\hline Nausea & $\leq 1 \mathrm{hr}$ & $1(4.2)$ & 0 & $>0.99$ \\
& $1 \mathrm{hr}<-\leq 6 \mathrm{hr}$ & $2(8.3)$ & 0 & 0.490 \\
& $6 \mathrm{hr}<-\leq 24 \mathrm{hr}$ & $3(12.5)$ & $2(9.1)$ & $>0.99$ \\
& $24 \mathrm{hr}<-\leq 48 \mathrm{hr}$ & $4(16.7)$ & 0 & 0.110 \\
Vomiting & $<48 \mathrm{hr}$ & $2(8.3)$ & 0 & 0.490 \\
Respiratory depression & $<48 \mathrm{hr}$ & 0 & 0 & \\
Toxicity of local & $<48 \mathrm{hr}$ & 0 & 0 & \\
$\quad$ anesthetics & & & & \\
Horner's syndrome & $<48 \mathrm{hr}$ & 0 & 0 & \\
\hline
\end{tabular}

Data are presented as number (\%).

Group C: retrolaminar injection with saline, Group R: retrolaminar block with local anesthetics.

24 hours postoperatively. A prospective randomized study by Onishi et al. [14] found that the RLB group had lower pain scores than the control group until 2 hours after surgery, but the requirement of the analgesic drug was similar after 12 hours postoperatively in both groups. However, Kairaluoma et al. [19] reported that a single administration of the TPVB for breast surgery reduced postoperative opioid consumption 1 hour after surgery, and that less overall pain intensity was observed 24 hours after the surgery. Previous studies on the TPVB reported that multi-level injection resulted in greater numbers of anesthetized dermatomes $[20,21]$. However, the postoperative pain scores
Table 3. The Satisfaction of Patient on Postoperative Pain Management

\begin{tabular}{cccc}
\hline Scale & Group $\mathrm{C}(\mathrm{n}=24)$ & Group $\mathrm{R}(\mathrm{n}=22)$ & $P$ value \\
\hline 1 & 0 & 0 & 0.213 \\
2 & 0 & 0 & \\
3 & $2(8.3)$ & 0 & \\
4 & $19(79.2)$ & $16(72.7)$ & \\
5 & $3(12.5)$ & $6(27.3)$ & \\
\hline
\end{tabular}

Data are presented as number (\%).

Group C: retrolaminar injection with saline, Group R: retrolaminar block with local anesthetics.

and morphine consumption were comparable between the single and multi-level injection groups [20]. Therefore, we postulated that the multi-level doses of RLB did not have a significant impact on postoperative analgesia compared to a single injection.

The principal mechanism of action in the RLB for analgesia can be explained by local anesthetic spreading anteriorly through the superior costotransverse ligaments into either the paravertebral space, epidural spaces, or intervertebral foramen [22]. A human cadaveric study suggested that the paravertebral space could not be a closed triangular space, and the superior costotransverse ligament could be a passage for the diffusion of local anesthetic [23]. Another cadaveric study, using magnetic resonance imaging and anatomical dissection, demonstrated that the RLB with $20 \mathrm{~mL}$ of injectate produced spread into the epidural 

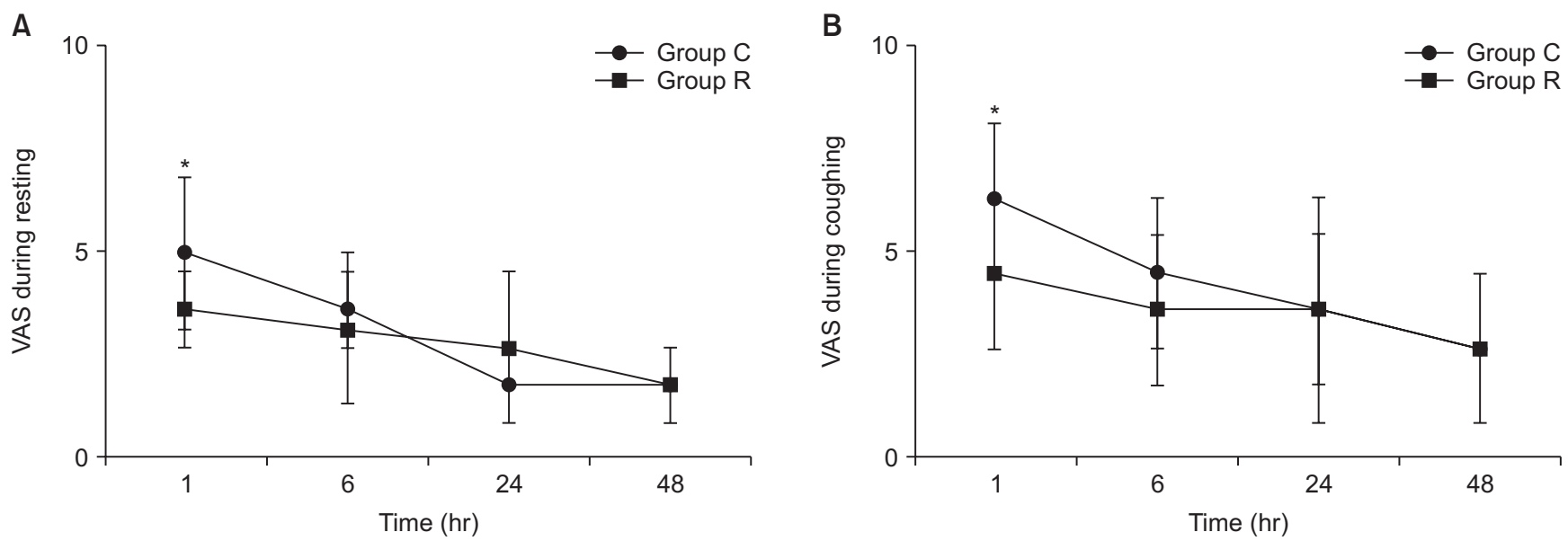

Fig. 3. (A) The visual analogue scale (VAS) of pain intensity during resting was evaluated at 1, 6, 24, and 48 hours after the operation. VAS during resting decreased in both groups as time passed and was higher in group $\mathrm{C}$ than group $\mathrm{R}$ at 1 hour postoperatively $(P=0.011)$. (B) VAS of pain intensity during coughing was assessed at 1, 6, 24, and 48 hours after the operation. VAS during resting decreased in both groups as time passed and was higher in group $\mathrm{C}$ than group $\mathrm{R}$ at 1 hour postoperatively $(P=0.004)$. Data were expressed as median \pm interquartile range. Mann-Whitney $U$-test was used for a comparison of the two groups at each measuring point, and rank transform for parametric factorial analyses using ANOVA procedures were performed to analyze the interaction between time and group. Group C: retrolaminar injection with saline, Group R: retrolaminar block with local anesthetics. ${ }^{*} P<0.05$ compared with group $\mathrm{C}$.

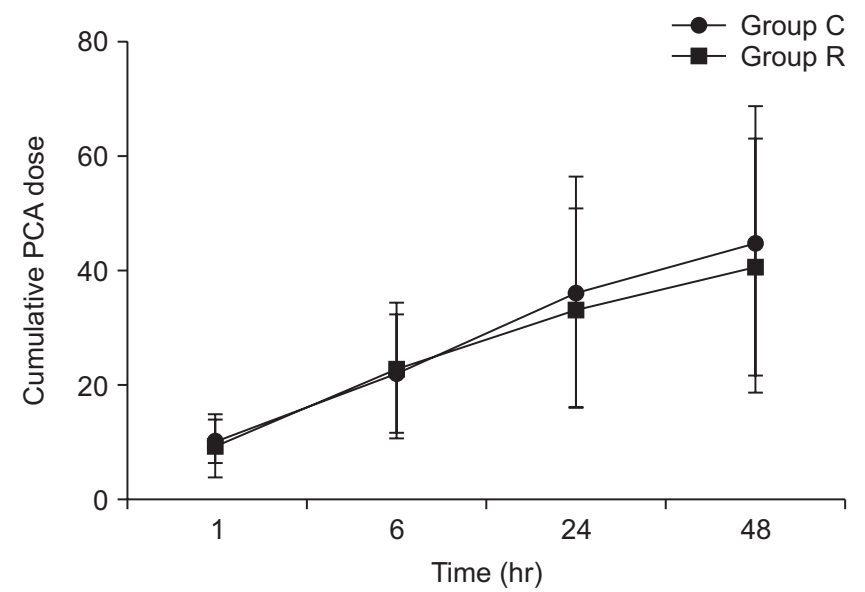

Fig. 4. The accumulated intravenous patient-controlled analgesia (IVPCA) dose was assessed at 1, 6, 24, and 48 hours after the operation. There was no significant difference between the two groups. Data are expressed as mean \pm standard deviation. Repeated measures ANOVA was performed to analyze the interaction between time and group.

and neural foramen spaces [24]. However, the pattern of injectate spread was variable [25], and the extent of paravertebral distribution could be volume-dependent [26]. Furthermore, most of these human anatomical studies had in common that the RLB was consistently associated with a large distribution of injectate posterior to the back muscle and with limited spread to the paravertebral block $[24,25,27]$. Thus, we postulated that the RLB could present a similar or less analgesic effect than the classic TPVB.

Our findings show that a single injection of ultrasoundguided RLB could be insufficient to reduce postoperative analgesic requirement in breast surgery. The analgesic effect of the RLB was limited possibly because of the following: insufficiency of local anesthetic spreading into TPVS, the delivery method of local anesthetics (single injection), and the complexity of breast innervation. The terminal elimination half-life of ropivacaine was approximately 4.2 hours following epidural administration, and anesthesia time in this study was approximately 3 hours $(180.0 \pm 33.8$ $\mathrm{min}$ ) in the RLB group [28]. Therefore, to maximize the effect of RLB and to effectively control postoperative pain, we suggest that this block should be performed at the end of the surgery. Considering a recent study on the erector spinae plane block, which is similar to the RLB [29], the continuous infusion method in the RLB could be a good option for adequate postoperative analgesia following breast surgery.

This study had some limitations. First, the exclusion criteria, regarding history of trauma or surgery to the thoracic vertebrae and structural abnormalities in the pleural space, which could affect local anesthetic spread into the TPVS, was not included. Nevertheless, none of the patients enrolled in our study had these problems. Second, the regional analgesic technique may give trauma to the patient if it is performed during general anesthesia, but ultrasound-guided RLB is safe and simple, so we performed it after the induction of general anesthesia to reduce patients' discomfort and to ensure double-blindness. However, the procedure during general anesthesia reduced the ease of the RLB and prevented a pinprick test for dermatomal distribution. Third, we calculated the sample size using data from the TPVB because there was a lack of studies 
on applying the RLB to breast surgery. Fourth, we used IVPCA with morphine alone to evaluate the effect of RLB on analgesic requirements. Evidence supports the combination of non-opioid systemic analgesics and opioids in PCA to improve analgesic efficacy and reduce opioid-related adverse events [30]. The use of acetaminophen or nonsteroid anti-inflammatory drugs could reduce the overall pain score and analgesic requirements in both the groups.

In conclusion, a single injection of ultrasound-guided RLB could not provide a postoperative opioid-sparing effect in breast surgery. The optimal timing and delivery method of local anesthetics for RLB require further investigation.

\section{CONFLICT OF INTEREST}

No potential conflict of interest relevant to this article was reported.

\section{FUNDING}

No funding to declare.

\section{ORCID}

Boo-Young Hwang, https://orcid.org/0000-0001-6098-0627 Eunsoo Kim, https://orcid.org/0000-0001-9978-4973 Jae-young Kwon, https://orcid.org/0000-0002-7472-8278 Ji-youn Lee, https://orcid.org/0000-0003-4741-8722 Dowon Lee, https://orcid.org/0000-0001-5140-2358 Eun Ji Park, https://orcid.org/0000-0002-7967-1127 Taewoo Kang, https://orcid.org/0000-0002-6279-0904

\section{REFERENCES}

1. Harris E, Barry M, Kell MR. Meta-analysis to determine if surgical resection of the primary tumour in the setting of stage IV breast cancer impacts on survival. Ann Surg Oncol 2013; 20: 2828-34.

2. Alves Nogueira Fabro E, Bergmann A, do Amaral E Silva B, Padula Ribeiro AC, de Souza Abrahão K, da Costa Leite Ferreira MG, et al. Post-mastectomy pain syndrome: incidence and risks. Breast 2012; 21: 321-5.

3. Chiu C, Aleshi P, Esserman LJ, Inglis-Arkell C, Yap E, Whitlock EL, et al. Improved analgesia and reduced postoperative nausea and vomiting after implementation of an enhanced recovery after surgery (ERAS) pathway for total mastectomy. BMC Anesthesiol 2018; 18: 41.
4. Hickey OT, Burke SM, Hafeez P, Mudrakouski AL, Hayes ID, Shorten GD. Severity of acute pain after breast surgery is associated with the likelihood of subsequently developing persistent pain. Clin J Pain 2010; 26: 556-60.

5. Terkawi AS, Tsang S, Sessler DI, Terkawi RS, Nunemaker MS, Durieux ME, et al. Improving analgesic efficacy and safety of thoracic paravertebral block for breast surgery: a mixedeffects meta-analysis. Pain Physician 2015; 18: E757-80.

6. Karmakar MK. Thoracic paravertebral block. Anesthesiology 2001; 95: 771-80.

7. Pace MM, Sharma B, Anderson-Dam J, Fleischmann K, Warren L, Stefanovich P. Ultrasound-guided thoracic paravertebral blockade: a retrospective study of the incidence of complications. Anesth Analg 2016; 122: 1186-91.

8. Albi-Feldzer A, Duceau B, Nguessom W, Jayr C. A severe complication after ultrasound-guided thoracic paravertebral block for breast cancer surgery: total spinal anaesthesia: a case report. Eur J Anaesthesiol 2016; 33: 949-51.

9. Kus A, Gurkan Y, Gul Akgul A, Solak M, Toker K. Pleural puncture and intrathoracic catheter placement during ultrasound guided paravertebral block. J Cardiothorac Vasc Anesth 2013; 27: e11-2.

10. Pfeiffer G, Oppitz N, Schöne S, Richter-Heine I, Höhne M, Koltermann C. Analgesia of the axilla using a paravertebral catheter in the lamina technique. Anaesthesist 2006; 55: 4237.

11. Voscopoulos C, Palaniappan D, Zeballos J, Ko H, Janfaza D, Vlassakov K. The ultrasound-guided retrolaminar block. Can J Anaesth 2013; 60: 888-95.

12. Zeballos JL, Voscopoulos C, Kapottos M, Janfaza D, Vlassakov K. Ultrasound-guided retrolaminar paravertebral block. Anaesthesia 2013; 68: 649-51.

13. Murouchi T, Yamakage M. Retrolaminar block: analgesic efficacy and safety evaluation. J Anesth 2016; 30: 1003-7.

14. Onishi E, Murakami M, Nishino R, Ohba R, Yamauchi M. Analgesic effect of double-level retrolaminar paravertebral block for breast cancer surgery in the early postoperative period: a placebo-controlled, randomized clinical trial. Tohoku J Exp Med 2018; 245: 179-85.

15. Valery P, Aliaksei M. A comparison of the onset time of complete blockade of the sciatic nerve in the application of ropivacaine and its equal volumes mixture with lidocaine: a double-blind randomized study. Korean J Anesthesiol 2013; 65: 42-7.

16. Rohan B, Singh PY, Gurjeet K. Addition of clonidine or lignocaine to ropivacaine for supraclavicular brachial plexus block: a comparative study. Singapore Med J 2014; 55: 229-32.

17. Das S, Bhattacharya P, Mandal MC, Mukhopadhyay S, Basu SR, Mandol BK. Multiple-injection thoracic paravertebral block as an alternative to general anaesthesia for elective breast surgeries: a randomised controlled trial. Indian J Anaesth 2012; 56: 27-33. 
18. Agarwal RR, Wallace AM, Madison SJ, Morgan AC, Mascha EJ, Ilfeld BM. Single-injection thoracic paravertebral block and postoperative analgesia after mastectomy: a retrospective cohort study. J Clin Anesth 2015; 27: 371-4.

19. Kairaluoma PM, Bachmann MS, Korpinen AK, Rosenberg PH, Pere PJ. Single-injection paravertebral block before general anesthesia enhances analgesia after breast cancer surgery with and without associated lymph node biopsy. Anesth Analg 2004; 99: 1837-43.

20. Kaya FN, Turker G, Mogol EB, Bayraktar S. Thoracic paravertebral block for video-assisted thoracoscopic surgery: single injection versus multiple injections. J Cardiothorac Vasc Anesth 2012; 26: 90-4.

21. Naja ZM, El-Rajab M, Al-Tannir MA, Ziade FM, Tayara K, Younes F, et al. Thoracic paravertebral block: influence of the number of injections. Reg Anesth Pain Med 2006; 31: 196201.

22. Onishi E, Toda N, Kameyama Y, Yamauchi M. Comparison of clinical efficacy and anatomical investigation between retrolaminar block and erector spinae plane block. Biomed Res Int 2019; 2019: 2578396.

23. Costache I, Sinclair J, Farrash FA, Nguyen TB, McCartney CJ, Ramnanan CJ, et al. Does paravertebral block require access to the paravertebral space? Anaesthesia 2016; 71: 858-9.

24. Adhikary SD, Bernard S, Lopez H, Chin KJ. Erector spinae plane block versus retrolaminar block: a magnetic resonance imaging and anatomical study. Reg Anesth Pain Med 2018; 43: 756-62.

25. Sabouri AS, Crawford L, Bick SK, Nozari A, Anderson TA. Is a retrolaminar approach to the thoracic paravertebral space possible?: a human cadaveric study. Reg Anesth Pain Med 2018; 43: 864-8.

26. Damjanovska M, Stopar Pintaric T, Cvetko E, Vlassakov K. The ultrasound-guided retrolaminar block: volume-dependent injectate distribution. J Pain Res 2018; 11: 293-9.

27. Yang HM, Choi YJ, Kwon HJ, O J, Cho TH, Kim SH. Comparison of injectate spread and nerve involvement between retrolaminar and erector spinae plane blocks in the thoracic region: a cadaveric study. Anaesthesia 2018; 73: 1244-50.

28. Simpson D, Curran MP, Oldfield V, Keating GM. Ropivacaine: a review of its use in regional anaesthesia and acute pain management. Drugs 2005; 65: 2675-717.

29. Hong B, Bang S, Chung W, Yoo S, Chung J, Kim S. Multimodal analgesia with multiple intermittent doses of erector spinae plane block through a catheter after total mastectomy: a retrospective observational study. Korean J Pain 2019; 32: 20614.

30. Schwenk ES, Mariano ER. Designing the ideal perioperative pain management plan starts with multimodal analgesia. Korean J Anesthesiol 2018; 71: 345-52. 